\title{
Replacing liquid fyrite with digital to improve in vitro fertilization laboratory quality control procedures
}

\author{
Casey A. McDonald ${ }^{1}$, Zachary A. Haimowitz ${ }^{1}$, Andrea DeVenuta ${ }^{1}$, Charity Reeves ${ }^{1}$, \\ Alan B. Copperman ${ }^{1,2}$, Jason Barritt ${ }^{1,2^{*}}$ \\ ${ }^{1}$ Reproductive Medicine Associates of New York, New York, USA \\ ${ }^{2}$ Reproductive Endocrinology, Mount Sinai School of Medicine, New York, USA \\ Email: *ibarritt@,rmany.com
}

Received 15 November 2011; revised 13 December 2011; accepted 5 January 2012

\begin{abstract}
In clinical in vitro fertilization (IVF), optimal culture conditions are required for production of high quality embryos and for achieving high pregnancy rates. Cell culture systems require vigilant attention to quality control and quality assurance, and upgrades to equipment and procedures require strenuous deliberation. During a 2-week maintenance period, we undertook an extensive analysis of incubator carbon dioxide $\left(\mathrm{CO}_{2}\right)$ monitoring and the effect on culture media $\mathrm{pH}$ by comparing our traditional liquid Fyrite instruments to a certified and calibrated digital $\mathrm{CO}_{2}$ analyzer. The digital analyzer produced consistently lower $\mathrm{CO}_{2}$ readings and significantly greater precision than the liquid Fyrite. Media pH measurements showed significant variation depending on $\mathrm{CO}_{2}$ calibration device; however $\mathrm{pH}$ remained within manufacturers' specifications. After superior performance by the digital analyzer, we incorporated this device into the incubator calibration and daily quality control procedures. A retrospective comparison of overall lab performance before and after this equipment switch demonstrated improved clinical pregnancy and implantation rates. This report illustrates the necessary caution when altering established laboratory procedures and equipment while highlighting the benefits of judiciously updating techniques and equipment in a laboratory setting that is often stubborn to change pre-existing, ingrained methodology.
\end{abstract}

Keywords: IVF; Incubator $\mathrm{CO}_{2}$; Laboratory Quality Control/Quality Assurance; Liquid Fyrite; Embryo Development; Embryo Culture

\section{INTRODUCTION}

The primary goal of the modern in vitro fertilization (IVF)

\footnotetext{
"Corresponding author.
}

laboratory is to optimize culture conditions to produce healthy embryos in effort to maximize implantation and pregnancy rates. IVF labs utilize highly complex systems to delicately culture embryos for 3 - 6 days. Doing so requires the utmost attention to detail in every aspect of laboratory procedures and maintenance of equipment. Embryo culture takes place in highly specialized media with tightly maintained nutrients and buffering agents. The embryos are placed in carefully monitored incubators controlling temperature, humidity and $\mathrm{CO}_{2} / \mathrm{O}_{2}$ levels. IVF labs encompass highly complex systems with hundreds of moving parts, each of which must be carefully managed with quality control and quality assurance (QC/QA) [1-4].

While technological advances are highly sought after, embryologists are often very cautious, if not recalcitrant, about altering standard procedures. As a result, existing and functioning methodologies do not readily change. In effort to improve our laboratory's method for QC/QA of incubator $\mathrm{CO}_{2}$ levels, we performed an extensive comparison of traditional liquid Fyrite and a Digital $\mathrm{CO}_{2}$ Analyzer during a scheduled laboratory maintenance period. Following superior performance of the calibrated and certified digital analyzer during the non-clinical maintenance period, we incorporated the digital device into clinical incubator calibration and daily $\mathrm{CO}_{2} \mathrm{QC}$ procedures. We then carefully monitored laboratory and clinical outcomes.

\section{MATERIALS AND METHODS}

Measurement of $\mathrm{CO}_{2}$ percentage in 13 HERAcell150 incubators using 2 liquid $0 \%-7 \% \mathrm{CO}_{2}$ Fyrite Gas Analyzers (Bacharach) and a digital Bacharach $2820 \mathrm{CO}_{2}$ Analyzer were performed. Measurements replicated the labs standard daily QC procedure, but added duplicate back-to-back measurements with both the liquid Fyrites and the digital instrument. Incubators were randomly grouped and $\mathrm{CO}_{2}$ calibrated to either the Fyrite or digital analyzer (Fyrite 5.5\% n = 5, Digital 5.5\% $\mathrm{n}=4$, Fyrite 
$6.0 \% \mathrm{n}=2$, Digital $6.0 \% \mathrm{n}=2$ ). Using an Oakton series $10 \mathrm{pH}$ analyzer, we took daily $\mathrm{pH}$ measurements of our standard culture media, Quinn's Cleavage (SAGE) and G2.5 (Vitrolife), after media had equilibrated $\sim 18 \mathrm{hrs}$.

Following the equipment comparison analysis, the laboratory switched all calibrations and daily $\mathrm{QA} / \mathrm{QC}$ protocol from the traditional liquid Fyrite system to the calibrated and certified digital analyzer. All other standard laboratory procedures remained constant throughout the period in which we compared the IVF success rates. We retrospectively compared data from before the switch $(90$ days) to after the switch (90 days) in order to assess overall clinical results including fertilization, biochemical and clinical pregnancy rates. Results were analyzed using ANOVA, $t$-test and $\chi^{2}$ with significance level $p<0.05$.

\section{RESULTS}

$\mathrm{CO}_{2}$ readings significantly differed between the 2 liquid Fyrite analyzers (A vs. B), and the digital analyzer (Table 1).

The digital analyzer consistently gave lower $\mathrm{CO}_{2}$ values for both the $5.5 \%$ and $6.0 \%$ calibrated incubators compared with the liquid Fyrites. Importantly, the electronic analyzer also displayed greater precision between repeated readings. All $\mathrm{pH}$ readings of the culture media remained within the manufacturer specifications, however there were differences in $\mathrm{pH}$; i.e. incubators calibrated with the digital analyzer resulted in significantly decreased $\mathrm{pH}$.

Based on the readings made during the laboratory maintenance period, the protocol for daily $\mathrm{QA} / \mathrm{QC}$ was changed from liquid Fyrite to digital monitoring of incubator $\mathrm{CO}_{2}$. A retrospective analysis of the overall lab performance prior to and following the switch to digital resulted in significant improvements in our overall im- plantation and clinical pregnancy rates (Table 2).

These improvements were seen across our standard IVF patient population in which we saw no significant changes in mean age, oocytes retrieved, fertilization rate, number of high quality Day 3 embryos or number of embryos cryopreserved. Notably, when analyzed separately from the standard IVF population, results for oocyte donor/recipient displayed no significant differences in success rates (Table 3).

\section{DISCUSSION}

Measuring $\mathrm{CO}_{2}$ levels using liquid Fyrite has been the standard QC protocol in labs for many years. Although the instrument is cumbersome, time consuming in use provides variable accuracy in results and it may be toxic to user and embryos; many labs are hesitant to switch techniques. In our preliminary equipment comparison, a calibrated digital analyzer produced significantly lower $\mathrm{CO}_{2}$ readings with less variation between readings. Subsequent incubator calibrations using the calibrated digital analyzer resulted in lower $\mathrm{pH}$ measured in culture media, although all levels remained within the manufacturers' specifications of acceptable values.

Following the superior performance of the digital analyzer we incorporated it into incubator calibration and daily QC procedures in place of the liquid fyrite within the clinical setting. Following the switch multiple aspects of laboratory maintenance were improved. Incubator $\mathrm{CO}_{2}$ was measured in less time, eliminating cumbersome fyrite equipment prone to failure. A volatile substance toxic to both embryos and users was eliminated from the lab environment and regular refills of the fyrite were no longer necessary. Finally, a digital readout offered a more objective value for $\mathrm{CO}_{2}$ levels than "eyeballing" a liquid level.

Table 1. Comparison of $\mathrm{CO}_{2}$ measuring and resulting $\mathrm{pH}$.

\begin{tabular}{|c|c|c|c|c|}
\hline $\begin{array}{c}\text { Incubator } \mathrm{CO}_{2} \% \text { and } \\
\text { Calibration Type }\end{array}$ & $\begin{array}{c}\text { Liquid Fyrite A } \\
\text { Mean } \pm \text { SD (Range) }\end{array}$ & $\begin{array}{c}\text { Liquid Fyrite B } \\
\text { Mean } \pm \text { SD (Range) }\end{array}$ & $\begin{array}{c}\text { Digital Analyzer } \\
\text { Mean } \pm \text { SD (Range) }\end{array}$ & pH \\
\hline $5.5 \%$ by Liquid & $\begin{array}{l}5.71 \pm 0.10^{*} \\
(5.61-5.81)\end{array}$ & $\begin{array}{c}5.5 \pm 0.19^{*} \\
(5.31-5.69)\end{array}$ & $\begin{array}{l}4.91 \pm 0.06^{*} \\
(4.85-4.97)\end{array}$ & $7.2^{+}$ \\
\hline $5.5 \%$ by Digital & $\begin{array}{l}6.11 \pm 0.10^{* *} \\
(6.01-6.21)\end{array}$ & $\begin{array}{l}5.98 \pm 0.30^{* *} \\
(5.68-6.28)\end{array}$ & $\begin{array}{l}5.72 \pm 0.07^{* *} \\
(5.65-5.79)\end{array}$ & $7.16^{+}$ \\
\hline $6.0 \%$ by Liquid & $\begin{array}{c}6.16 \pm 0.09^{* * *} \\
(6.07-6.25)\end{array}$ & $\begin{array}{c}5.98 \pm 0.18^{* * *} \\
(5.80-6.16)\end{array}$ & $\begin{array}{c}5.59 \pm 0.16^{* * *} \\
(5.43-5.75)\end{array}$ & $7.26^{++}$ \\
\hline 6.0\% by Digital & $\begin{array}{c}6.45 \pm 0.12 \\
(6.33-6.57)\end{array}$ & $\begin{array}{c}6.26 \pm 0.28 \\
(5.98-6.54)\end{array}$ & $\begin{array}{c}6.10 \pm 0.07 \\
(6.03-6.17)\end{array}$ & $7.24^{++}$ \\
\hline
\end{tabular}

Comparison of $\mathrm{CO}_{2}$ levels denoted by asterisks; comparison of $\mathrm{pH}$ levels denoted by plus signs. ${ }^{*} p<0.05$ between the numbers in row " $5.5 \%$ by Liquid"; ${ }^{* *} p<0.05$ between the numbers in row " $5.5 \%$ by Digital"; ${ }^{* * *} p<0.05$ between the numbers in row " $6.0 \%$ by Liquid"; ${ }^{+} p<0.05$ between the Liquid and Digital $\mathrm{pH}$ values at $5.5 \% \mathrm{CO}_{2} ;{ }^{++} p<0.05$ between the Liquid and Digital $\mathrm{pH}$ values at $6.0 \% \mathrm{CO}_{2}$. 
Table 2. Clinical results for oocyte donor cases before and after the digital switch.

\begin{tabular}{llll}
\hline & $\begin{array}{l}\text { IVF Cases-Liquid } \\
\text { Fyrite }\end{array}$ & $\begin{array}{l}\text { IVF Cases-Digital } \\
\text { Analyzer }\end{array}$ & p Value \\
\hline Embryo Transfers & 386 & 373 & \\
Biochemical Pregnancy & 224 & 242 & 0.06 \\
Biochemical Pregnancy \% & $58.0 \%$ & $64.9 \%$ & \\
Clinical Pregnancy (Sac) & 182 & 208 & 0.021 \\
Clinical Pregnacny \% & $47.2 \%$ & $55.8 \%$ & 0.13 \\
Oocyte Age & $36.5 \pm 4.5$ & $35.9 \pm 4.9$ & 0.13 \\
Oocytes Retrieved & $14.5 \pm 8.8$ & $13.6 \pm 8.2$ & 0.53 \\
Fertilization Rate per Mature Oocyte & $75.2 \%$ & $75.9 \%$ & 0.97 \\
Ongoing Embryos-Day 3 & $7.1 \pm 5.2$ & $7.1 \pm 5.5$ & 0.6 \\
High Quality Embryos Ongoing-Day 3 & $4.3 \pm 3.9$ & $4.2 \pm 4.1$ & 0.75 \\
Day 3 Embryo Transfers \% & $75.1 \%$ & $73.8 \%$ & 0.81 \\
Average Number of Embryos Transferred & $2.8 \pm 1.3$ & $2.7 \pm 1.3$ & $* 0.009$ \\
Implantion Rate & $25.4 \%$ & $30.6 \%$ & 89 \\
Embryos Cryopreserved & 100 & $23.9 \%$ & 0.67 \\
Embryos Cryopreserved \% & $25.9 \%$ & $3.1 \pm 2.4$ & 0.21 \\
Embryos Cryopreserved Per Case & $2.7 \pm 1.9$ & & \\
\hline
\end{tabular}

Table 3. Clinical results for oocyte donor cases before and after the digital switch.

\begin{tabular}{llll}
\hline & $\begin{array}{l}\text { Donor Oocyte Cases-Liquid } \\
\text { Fyrite }\end{array}$ & $\begin{array}{l}\text { Donor Oocyte Cases-Digital } \\
\text { Analyzer }\end{array}$ & p Value \\
\hline Embryo Transfers & 37 & 49 & \\
Biochemical Pregnancy & 24 & 31 & 0.92 \\
Biochemical Pregnancy \% & $64.9 \%$ & $63.3 \%$ & \\
Clinical Pregnancy (Sac) & 20 & 27 & 0.92 \\
Clinical Pregnacny \% & $54.1 \%$ & $55.1 \%$ & 0.88 \\
Oocyte Age & $26.6 \pm 3.6$ & $26.7 \pm 2.8$ & 0.42 \\
Fertilization Rate per Mature Oocyte & $77.7 \%$ & $80.4 \%$ & 0.38 \\
Average Number of Embryos Transferred & $2.3 \pm 0.6$ & $2.4 \pm 0.5$ & 0.7 \\
Implantion Rate & $34.1 \%$ & $30.5 \%$ & \\
Embryos Cryopreserved & 13 & 20 & 0.75 \\
Embryos Cryopreserved \% & $35.1 \%$ & $40.8 \%$ & 0.09 \\
\hline Embryos Cryopreserved Per Case & $3.1 \pm 1.7$ & $2.2 \pm 1.2$ & \\
\hline
\end{tabular}

We undertook this study in 2 distinct steps, showing increased precision for $\mathrm{CO}_{2}$ and $\mathrm{pH}$ and then ultimately an overall clinical improvement after transition to the new electronic analyzer. We intensively monitored our laboratory and clinical results before and after the switch. Our findings demonstrate overall improved rates for clinical pregnancy and implantation. Though we did not see improvements in the success rates for our donor/recipient population, we show confidently that this major laboratory procedural change did not adversely affect overall laboratory conditions.

Reference [5] showed the variable results between technicians and different fyrite devices. Despite the known variability and limited accuracy, the cost of purchasing new devices and reluctance to alter ingrained methodology has remained to be a barrier to universal conversion to digital devices. Reference [6] analyzed the practices of highly successful IVF centers. Points of 
emphasis included "attention to detail" and "stringent QC". We believe our cautious incorporation of a new QC technology demonstrates these principles and furthermore illustrates how highly efficient IVF centers can continue to improve their success rates through the application of newer and more precise technologies.

\section{REFERENCES}

[1] Higdon, H.L., Blackhurst, D.W. and Boone, W.R. (2008) Incubator management in assisted reproductive technology laboratory. Fertility and Sterility, 89, 703-710. doi:10.1016/i.fertnstert.2007.03.040

[2] Pool, T.B. (2004) Optimizing pH in clinical embryology.
Clinical Embryologist, 7, 1-17

[3] Lane, M. and Gardner, D. (2003) Towards a single embryo transfer. Reproductive BioMedicine Online, 6, 470481. doi:10.1016/S1472-6483(10)62170-0

[4] Lane, M. and Gardner, D. (2004) The road to single embryo transfer. Clinical Embryologist, 7, 1-26.

[5] Johnson, J.E., Boone, W.R., Lee, S.T. and Blackhurst, D.W. (1995) Using fyrite to monitor incubator carbon dioxide levels. Journal of Assisted Reproduction and Genetics, 12, 113-117. doi:10.1007/BF02211379

[6] Van Voorhis, B.J., Thomas, M., Surrey, E.S. and Sparks, A. (2010).What do consistently high-performing in vitro fertilization programs in the U.S. do? Fertility and Sterility, 94, 1346-1349. doi:10.1016/j.fertnstert.2010.06.048 